\title{
Cresarean Section in the Treatment of Placenta Prævia.
}

\author{
By Beckwith Whitenouse, M.S. (Lond.), F.R.C.S. (Eng.), \\ Honorary Obstelric Surgeon, General Hospital, Birmingham.
}

To Lawson Tait must be accorded the credit of first suggesting the application of the Casarean operation for the relief of placenta prævia. The suggestion at the time received but little support, but served to initiate a discussion which has continued with varying intermissions until the present day. With the passing of the years and the perfecting of the technique of Cæsarean section, the trend of opinion has undergone a change, as regards the indications for the operation, and in no instance has this been more marked than in the case of placenta previa. In the light of recent discussions it is very interesting to turn to the expressions of opinion ten or twelve years ago, when very definite statements were made on the subject. IIenry Jellett, for example, in a paper read before the Obstetrical and Gynæcological Section of the Royal Society of Medicine on August 14th 1910, said that with regard to reducing the maternal mortality " there does not appear to be any place for Cesarean section in the modern treatment of uncomplicated cases of placenta prævia." Also, concerning the reduction of foetal mortality, Jellett thought that "the results were disappointing." This opinion was based upon his "Rotunda", experience, and also upon views expressed by IFarrison, Jewett, Fry, Newell, and Grandin at the April meeting of the American Gynæcological Society in 1909. In 1910, Krönig and Selheim (Berl. Med. Wochenschr., I9Io, xlvii, p. 7) published " 26 cases of placenta previa treated by Cesarean section, all the mother's recovering and all the children being born alive." The tendency at the London meeting in 1910, however, was to discount the Krönig figures, and to regard the cases as " picked."

Little of importance on the subject was published subsequently until I920 when a discussion upon the treatment of ante-partum hæmorrhage was held at the Royal Society of Medicine, at a combined meeting of the Section of Obstetrics and Gynæcology, North of England and Midland Obstetrical and Gynæcological Societies. It was evident that a distinct change of opinion had occurred during the interyening ten years. During this time the Cæsarean operation had been developed, and its possibilities, risks 
and dangers defined, chiefly as the result of Amand Routh's important publication in I9IO.

The majority of the speakers at the 1920 discussion, all practising obstetricians, and representing the chief teaching centres in the country, instead of condemning Casarean section for placenta prævia, considered that it occupied a definite place in its treatment, and some were whole-heartedly in favour of it as a routine method of treatment. This opinion was recently confirmed at the I92 I meeting of the British Medical. Association in Newcastle, when Munro Kerr and Eardley Holland opened a discussion upon the "Indications for Cresarean Section." Interest in the question is not confined to this country, as is shown by the publications in the Continental and American Medical Press during the past year. Papers have appeared by Gonzàles, Guèniot, Rấmos and Perez, Moran and others, all showing most favourable results both to mother and child from the application of the Cæsarean operation to placenta prævia.

Now that the operation has apparently proved its value in dealing successfully with certain cases of this obstetric complication, it will be of interest during the ensuing years to note whether it is able to maintain its position. To do this it must conform to three postulates :-

r. The existing maternal mortality from older methods of treatment must not be raised.

2. The subsequent maternal morbidity must not be increased.

3. The foetal mortality must be appreciably lowered.

That there is room for considerable improvement in the older methods of treatment of placenta prævia is evident from a consideration of the results of institutional treatment over a number of years. When discussing the right or wrong of any method of treatment involving operative procedure it is impossible to eliminate the personal equation. The same method may be attended by very different results in the hands of two individuals. Further, it is well known how, from time to time, various methods are advocated as being the ideal by certain enthusiasts, which further experience proves to be but an abnormal run of luck. In order to arrive therefore at the unvarnished facts, recourse must be had to the published reports of public institutions of which the staffs are constantly changing, and in which an individual's work forms but a part of the whole. From a critical survey of the facts and figures contained therein, it is possible, without bias or prejudice, to arrive at certain conclusions.

For the purpose of forming an opinion upon the relative influence of certain obstetric operations upon fœtal mortality, the 
writer of this review recently examined the Annual Reports of the Birmingham Maternity Hospital over a period covering the last ten years. The results of the investigation are published in extenso in the Report of the Royal Sanitary Congress held in Birmingham in 1920.

During this investigation the high maternal and foetal mortality for placenta prævia became at once evident: In the period under review, 3 I 7 cases of this complication were admitted to the hospital, out of a total of 5,591 admissions, i.e., a percentage of 5.6. Of these, 18 mothers died, a mortality of 5.6. Of the babies, 212 were stillborn, and 33 more died in hospital, a gross foetal mortality of 77.2 per cent.

During these ten years, eleven methods of delivery have been practised in the Institution, with the results shown in the appended table.

\section{TABLE I.}

Showing Methods of Delivery in Placenta Prequia. Method.

Fœtal Percent- Maternal Per-

Cases. Death. age. Death centage.

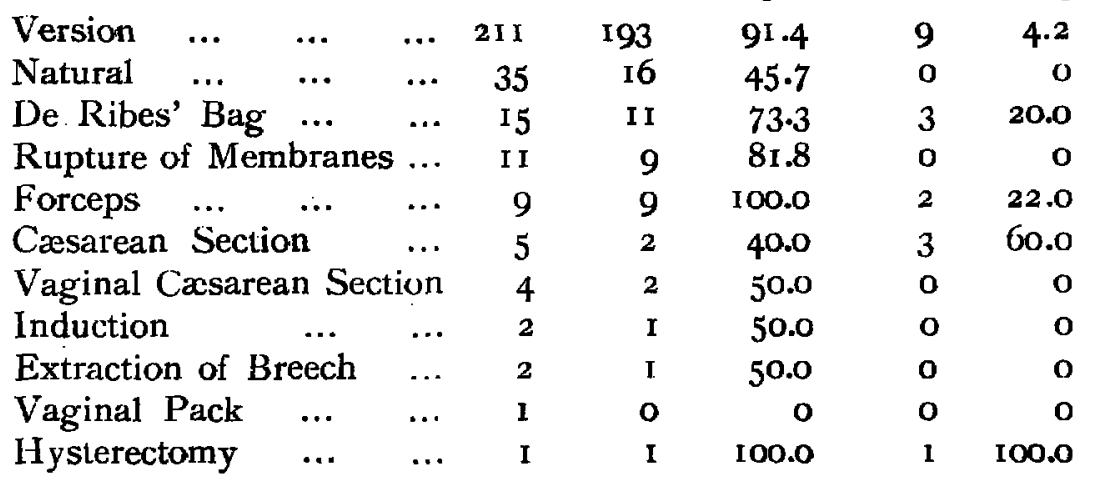

The favourite method of treatment was the time-honoured one of version. It is interesting to note, however, that in 211 women delivered by this means, the maternal death-rate was 4.2 per cent., and the foetal death-rate 9I.4 per cent. The maternal deaths were in part due to hæmorrhage and in part to sepsis.

If delivery could be left to nature, and by that it is presumed that the degree of hæmorrhage was not so severe as to call for immediate action, it is recorded that of a total of 35 cases, the maternal deaths were nil. The fotal deaths registered 16 , a percentage of 45.7 . Improvement in the fotal mortality is due partly to the lesser amount of hamorrhage, and partly to the fact that the risk of breech presentation is not super-added to that of ante- 
partum bleeding. In other words, the cases which may be left to nature are the minor degrees of lateral or marginal insertion of the placenta, and here one would naturally expect a lessened mortality, both maternal and fotal.

The application of De Ribes' Bag in 15 cases was associated with a maternal mortality of 20 per cent., and a fœtal death-rate of 73.3 per cent. There is no doubt in the history of obstetrics that De Ribes' Bag has in the past rendered valuable service, but with the choice of other surgical and more cleanly methods, it appears possible to-day to eliminate the risks attended by its use.

With regard to rupturing the membranes, obviously a method which can only be adopted in marginal or lateral cases, the maternal mortality is low, as is to be expected. Of II cases in which this was the method employed, all the mothers recovered. Unfortunately, however, 9 of the I I babies were stillborn, a fact which mars the total result, and points to a too late diagnosis and treatment.

As to forceps, only 9 cases of placenta prævia were treated by this method of delivery in ten years, but these nine cases accounted for the death of two mothers and the whole of the children. Forceps delivery in the presence of this complication is evidently highly dangerous to mother and child alike.

The five methods noted cover those most frequently in use in institutional practice in Birmingham during the last ten years, as shown by the published reports. Of a total of $28 \mathrm{I}$ cases of placenta prævia so treated, 238 babies died and 14 mothers, percentages respectively of 84.7 per cent. and 4.9 per cent.

Further, since placenta prævia accounted for $3^{\text {I. }} 3$ per cent. of the total number of still-births occurring in the Birmingham Maternity Hospital during the period under consideration, figures reaching 715 , the problem of treatment is one of considerable importance.

In order to lower appreciably the existing mortality rates, early diagnosis of this complication is the first step. Every case of antepartum hæmorrhage is not necessarily duc to placenta prævia, but every case of ante-partum hæmorrhage calls for the most careful pelvic examination.

When the placenta has a low insertion, the lower uterine segment in nine cases out of ten presents a different consistence from the normal. It does not possess that degree of elasticity which the normal uterine wall presents, and this fact has been found a useful diagnostic sign.

Further, if the hamorrhage has been so severe as to fill the lower uterine segment with clot, which may resemble placental tissue to the examining finger, the diagnosis is not of so great 
moment, as the life of the foetus has probably already been sacrificed.

Placenta prævia should be recognized if possible before bleeding has been so severe as to interfere with the vitality of the foetus. The first hæmorrhage is therefore the danger signal and the indication for careful pelvic examination. If this initial hæmorrhage has not been sufficiently severe to affect the vitality of the child, and the pregnancy has advanced to the eighth month, time should not be lost in an endeavour to see what nature will do.

In the reports of the Institution upon which this review is based, a case is recorded of a woman admitted for central placenta prævia, who was delivered by Cæsarean section and who subsequently died. A note is attached to the effect that this woman had been bleeding continuously for ten days before admission. It is little to be wondered at that she died, and the operation cannot be blamed for her death. If the woman had been admitted for treatment upon the first day of the bleeding who is to say that she would not have recovered?

In view of the series of cases recently published in which both the maternal and fotal mortality of Cæesarean section for placenta prævia has been nil, it is evident that the pendulum is swinging more and more in favour of abdominal section as being the ideal method of treatment for this obstetric complication. What is necessary, is to define the limits of the operation in this connection, in other words to establish a standard whereby it is possible to say that the indication is absolute in distinction to occasions when it is but relative or uncalled for.

It is, for example, unnecessary to propose the Cæsarean operation as a routine when the placenta is but marginal and when it is reasonable to suppose that delivery by other methods will be attended by the best results. It also appears wrong to submit a patient to the risks of abdominal operation when from the severity of the initial hæmorrhage it is to be assumed that there is little possibility of a living child being born. Nothing is to be gained by performing Cæsarean section in such circumstances, and if it is adopted on any and every occasion it will, sooner or later, become discredited.

The writer's practice is to reserve Cæasarean section for those cases of placenta prævia causing symptoms from the eighth month of pregnancy onwards, and when the first hæmorrhage has not been so severe as to risk the vitality of the child. Acting on these indications, 9 cases of central and lateral placenta prævia have been so treated during the past three years by the Cæsarean operation. Two of the cases were examples of binovular twin pregnancy, one placenta being "pravia" and the other situated on the anterior 
uterine wall. All the mothers recovered, and I I living children were born. Nine of the infants were alive and well one month after the operation, I infant died a few hours after birth, and one survived the operation only 7 days.

The question is sometimes raised as to the right procedure to adopt when the services of an experienced surgeon are not available. It is possible that cases will arise when the ideal cannot be obtained, and recourse must be had to the older and less satisfactory therapeutic measures. At the same time, with modern facilities of transport and the development of the Cottage Hospital and Nursing Home, it is difficult to imagine that the occasion can be very. frequent when skilled help is not at hand. Further, it is surprising what excellent results can be obtained under stress of circumstances, even in a cottage or slum, when it is impossible to transport the patient to hospital, if only ordinary surgical cleanliness is observed. 